\title{
Efficacy of Topical 5\% 5-Fluorouracil and 0.05\% Tretinoin and Electrosurgery in the Treatment of Plane Warts: A Randomized Controlled Comparative Trial
}

\author{
Singh $\mathbf{R}^{1}$, Pandey $\mathbf{S S}^{2}$
}

${ }^{1}$ Assistant Professor, Department of Dermatology, Heritage Institute of Medical Sciences,India; ${ }^{2}$ Professor, Department of dermatology, Heritage Institute of Medical Sciences, India

\begin{abstract}
Introduction: Human papilloma virus (HPV) is capable of causing varieties of dermatological conditions differing in morphology, histopathology and site of occurrence. Plane wart is one of the morphological variants accounting for approximately one fifth of HPV lesions. Treatment of plane warts is difficult and recurrence quite common.

Objectives: To compare the efficacy and safety of $5 \% 5$-fluorouracil ( $5 \mathrm{FU}$ ) and $0.05 \%$ tretinoin and electrosurgery in the treatment of plane wart.

Materials and methods: Seventy-five patients, 38 males and 37 females were included in this randomized controlled comparative trial. Patients were age and sex matched and divided into three groups, GROUP A: Patients treated with $5 \%$ 5-FU, GROUP B: Patients treated with 0.05\% tretinoin and GROUP C: Patients treated with electrosurgery. While topical treatments were applied once nightly for 4 weeks (5\% 5-FU for four hours and tretinoin overnight), electrosurgery was done at first visit only.

Result: While electrosurgery had shown faster results, results were more consistent with least recurrence in 5-FU and fair recurrence with $0.05 \%$ tretinoin.

Conclusion: All three treatments i.e. $5 \mathrm{FU}$, topical tretinoin and electrosurgery showed excellent response in treatment of plane warts with minimal side effects.

Key words: Electrosurgery; Flurouracil; Tretinoin; Warts
\end{abstract}

\section{Introduction}

$\mathrm{P}$ lane warts are benign growths of skin, presenting as small, flat, smooth elevated lesions caused by human papilloma virus (HPVs). Plane warts occur mostly in children and young adults with face, back of the hands and the shins being the commonly affected sites. ${ }^{1,2}$ Many treatment modalities have been tried, but none has proved to be uniformly effective. Whatever therapy we use for warts, failures and recurrences do occur. $^{3}$ 5-fluorouracil (5-FU) is a pyrimidine analogue that interferes with DNA synthesis by irreversibly inhibiting thymidylate synthetase, thus preventing cellular proliferation and resulting in cell death (preferentially affects rapidly dividing cells). ${ }^{4}$ 5-FU has been used in the treatment of plane warts. ${ }^{5}$ Retinoids

Funding: No

Conflict of Interest: No

\section{Address of Correspondence}

Dr. Rashmi Singh

Flat No. 502, Rudra Tower, Block A, Sundarpur Varanasi, Uttar

Pradesh- 221002, India

E-mail: sweetrashmi4364@gmail.com exert their physiologic action on DNA transcription by binding to two distinct families of nuclear receptors, RARs and RXRs. Topical retinoids have been used successfully in treatment of plane warts with a variable success rate. ${ }^{6,7}$ Electrosurgery is a treatment modality, based on the principle of tissue destruction by heat. ${ }^{8}$ But this method harbors the disadvantage of pain, scarring, respiratory papillomatosis in the operator and high recurrence. Electrofulguration is comparatively less effective in treatment of plane wart as compared

Submitted: $4^{\text {th }}$ April 2020

Accepted: $3^{\text {rd }}$ August 2020

Published: $20^{\text {th }}$ February 2021

How to cite this article

Singh R, Pandey SS. Efficacy of Topical 5\% 5-Fluorouracil and $0.05 \%$ Tretinoin and Electrosurgery in the Treatment of Plane Warts: A Randomized Controlled Comparative Trial. Nepal Journal of Dermatology, Venereology \& Leprology 2021;19(1):55-9. https://doi.org/10.3126/njdvl.v19i1.28322.

Licensed under CC BY 4.0 International License which permits use, distribution and reproduction in any medium, provided the original work is properly cited. 
to 5-FU and 5-FU has similar efficacy to that of topical tretinoin. The strength of our study is that we have compared three therapeutic modalities for plane wart while most studies till date have compared two in its treatment and electrosurgery seemed to show better clearance rate than either of the topical treatments (5-FU 5\% and tretinoin $0.05 \%$ ) at eight weeks follow up.

\section{Materials and Methods}

\section{Study design}

A randomized controlled comparative therapeutic trial was conducted at the Department of Dermatology and Venereology, Patna Medical College, Patna, Bihar from January 2017 to March 2017. All new cases of plane warts attending the Outpatient Department of Dermatology \& Venereology of Patna medical College were included in the study. Following patients were excluded from the study: a. Pregnant and lactating females, b. Patients with cardiac pacemakers c. patients who had taken any form of prior treatment for treatment of plane warts. Seventy-five patients; 38 males $(50.67 \%)$ and 37 females $(49.33 \%)$ were enrolled in this study. A written questionnaire was given to each patient to get full demographic information including their name, age, sex, occupation, marital status and also about the duration of disease, family history of warts, past medical history (for e.g. states of immune suppression due to drug or disease and any previous treatment for warts. Each patient was examined, after which photographs were taken using the same digital camera (Sony /cyber shot) keeping view and distance approximately the same. The numbers of lesions were calculated. After a full explanation to each patient about the nature of the disease, course, prognosis and full information related to the therapy including; the side effects, action and the way of application, the patients were randomly assigned to one of the treatment arms: 5 -fluorouracil ointment (5\%), topical tretinoin cream $(0.05 \%)$ or electrosurgery (using random number table method). The ethical approval was obtained from the ethical committee of Patna Medical College.

Group A: Patients treated with topical 5- FU skin ointment $5 \%$ for four hours once at night then washed.

Group B: Patients were treated with overnight topical tretinoin cream $0.05 \%$.

Group C: Patients were treated with electrosurgery.

In first two groups, patients were instructed to apply the drug once daily at night for four weeks duration to be evaluated for the response to treatment and to record any possible local and systemic side effects at the end of 4th and 8th week of therapeutic regimen respectively.

The response to treatment was graded as follows: $1=$ Good response ( $\leq 50 \%$ reduction in number of lesions) $2=$ significant response $(51-75 \%$ reduction in number of lesions) 3= excellent response $(76-100 \%$ reduction in number of lesions.)

All patients were examined at the end of 4th week and $8^{\text {th }}$ week to evaluate the response to treatment depending on clinical and photographic assessment and to record any possible local side effects. Data was analyzed using Minitab software. Chi-square and ANOVA were used to test the significance differences between proportions and means respectively. The $p$-value of $\leq 0.05$ was considered to be statistically significant. Lesions with superficial crust formation and clearance of lesions were considered to be end point for electrosurgery and topical treatment respectively.

\section{Results}

Demographic data of the studied population are shown in Table 1. The difference between the three groups in the age and gender distribution was statistically insignificant which implies a good randomization.

Group A (5\% 5-FU): After four weeks of treatment, all of the patients showed response to the treatment. Fifteen patients (53.57\%) showed an excellent response while nine patients (32.14\%) showed a good response. Patients with fair response were four (14.29\%). (Table2) After eight weeks, the number of patients with excellent responses rose to 24 (53.57\%). (Table 3)

Group B (Topical tretinoin 0.05\%): At fourth week, 13 (48.15\%), eight $(26.93 \%)$ and six $(22.22 \%)$ patients respectively had shown excellent, good and fair response to the treatment (Table2) and at the end of eighth week, $48.15 \%$ patients had shown excellent response. (Table 3)

Group C (Electrofulguration): Patients with fair, good and excellent response respectively were three (15\%), seven (35\%) and $10(50 \%)$ at fourth week (Table2) and $90 \%$ patients had their lesions cleared at the end of eight weeks. (Table 3)

Pain, burning sensation, erythema, hypopigmentation and scaring were the side effects noticed in the three groups however they were not statistically significant ( $p$-value=0.6478). (Table 4) 
Table 1: The distribution of patients according to the age and gender in the three groups

\begin{tabular}{|c|c|c|c|c|c|c|c|}
\hline Groups & $\mathbf{5 - F U}$ & & \multicolumn{2}{|c|}{ Tretinoin } & \multicolumn{2}{|c|}{ Electrofulguration } & p-value \\
\hline Gender & $\mathbf{n}$ & Mean age \pm SD & $\mathbf{n}$ & Mean age \pm SD & $\mathbf{n}$ & Mean age \pm SD & \\
\hline Male & 14 & $15.07 \pm 4.01$ & 14 & $13.50 \pm 3.29$ & 10 & $15 \pm 3.77$ & 0.3674 \\
\hline Female & 14 & $13.93 \pm 4.02$ & 13 & $14.38 \pm 3.75$ & 10 & $13.9 \pm 3.33$ & 0.9363 \\
\hline Total & 28 & $14.5 \pm 4.05$ & 27 & $13.93 \pm 3.54$ & 20 & $14.45 \pm 3.59$ & 0.8036 \\
\hline p-value & & 0.4593 & & 0.5220 & & 0.4980 & \\
\hline
\end{tabular}

Table 2: Difference in Response between three groups at 4 weeks

\begin{tabular}{|l|c|c|c|c|c|}
\hline Groups & Fair Response $\mathbf{n}(\%)$ & Good Response $\mathbf{n}(\%)$ & Excellent Response $\mathbf{n}(\%)$ & Total $\mathbf{n}(\%)$ & $\mathbf{p}$-value \\
\hline 5-FU & $4(14.2)$ & $9(32.14)$ & $15(53.57)$ & $28(100)$ & \\
\hline Tretinoin & $6(22.22)$ & $8(29.63)$ & $13(48.15)$ & $27(100)$ & 0.942 \\
\hline Electofulguration & $3(15)$ & $7(35)$ & $10(50)$ & $20(100)$ & \\
\hline
\end{tabular}

Table 3: Difference in response between three groups at 8 weeks

\begin{tabular}{|l|c|c|c|c|c|}
\hline Groups & Fair Response $\mathbf{n}(\%)$ & Good Response $\mathbf{n}(\%)$ & Excellent Response $\mathbf{n}(\%)$ & Total $\mathbf{n}(\%)$ & $\mathbf{p}$-value \\
\hline 5-FU & $2(14.2)$ & $2(32.14)$ & $24(53.57)$ & $28(100)$ & \\
\hline Tretinoin & $2(22.22)$ & $3(29.63)$ & $22(48.15)$ & $27(100)$ & 0.939 \\
\hline Electofulguration & $1(5)$ & $1(5)$ & $18(90)$ & $20(100)$ & \\
\hline
\end{tabular}

Table 4: Side effect profile of patients in different treatment groups

\begin{tabular}{|l|c|c|c|c|}
\hline Side effects & 5-FU $\mathbf{n ~ ( \% ) ~}$ & Tretinoin $\mathbf{n ~ ( \% ) ~}$ & Electofulguration $\mathbf{n}$ (\%) & p-value \\
\hline Pain & (19) 67.88 & (13) 48.15 & (18) 90 & \\
Burning & $(22) 78.57$ & $(14) 51.85$ & (5) 25 & \\
Erythema & $(23) 82.14$ & $(17) 62.96$ & $(2) 10$ & 0.6478 \\
Hypopigmentation & - & $(12) 44.44$ & (8) 40 & \\
Scarring & 0 & - & (4) 20 & \\
\hline
\end{tabular}

Photographs of patients pre and post various treatment modalities

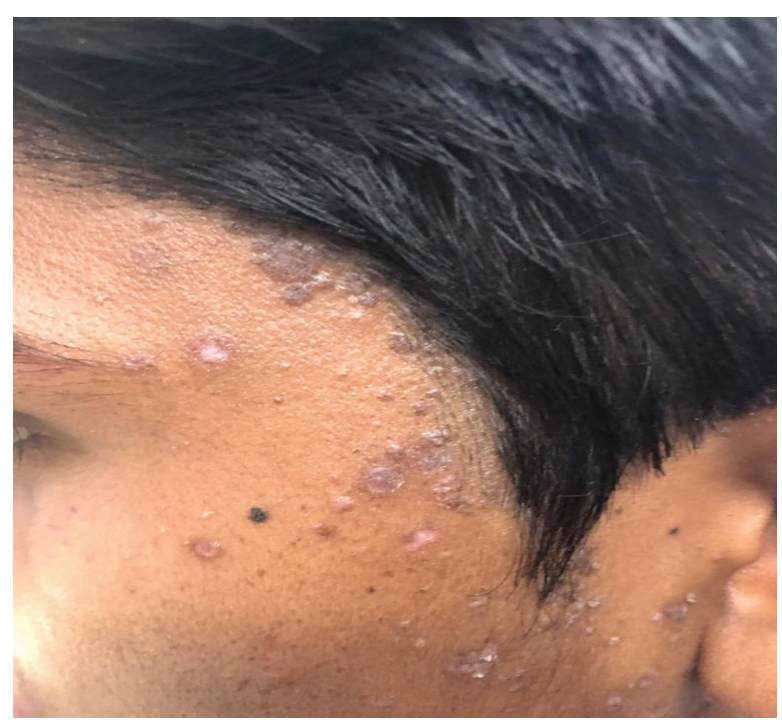

1 week post tretinoin

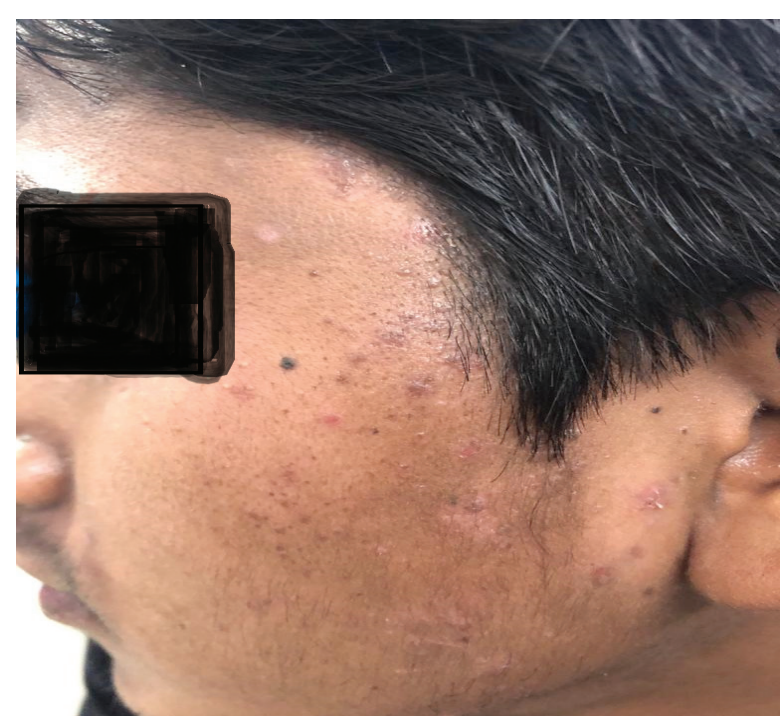

2 week post tretinoin 


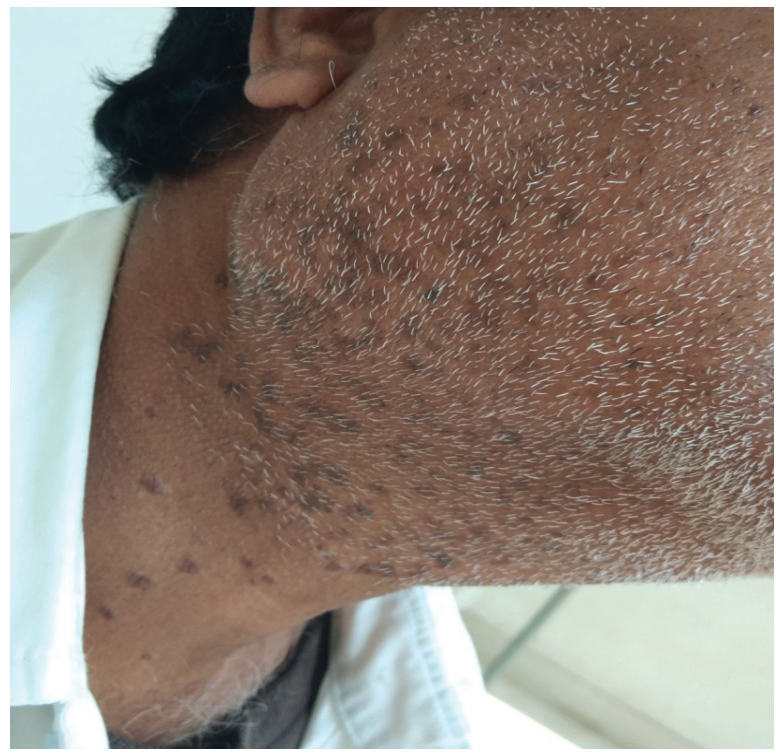

Baseline photo (Prior to Electrosurgery)

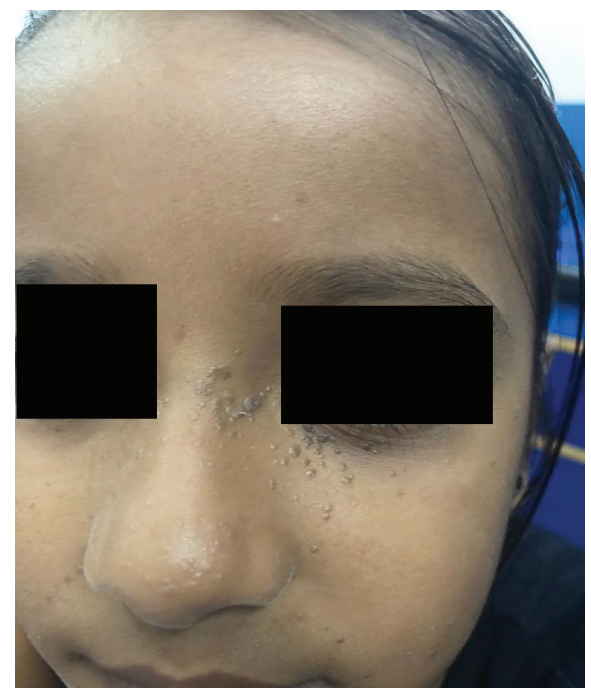

Baseline photo

\section{Discussion}

In a study done by Dogra A et al., 5-FU had higher success rate $(100 \%)$ as compared to radiofrequency ablation (80\%) in treatment of plane wart. ${ }^{10}$ While in our study, electrosurgery has shown excellent response (90\%) as compared to 5- FU( $48.15 \%$ ) patients at eight weeks. In our study, retinoid has shown excellent response in $81.48 \%$ which is consistent with $84.6 \%$ clearance seen with topical tretinoin $0.05 \%$ in a study done by EP Kubeyinje in $1995 .^{7}$ Lee $\mathrm{S}$ et al. reported clearance in 9 out of 11 patients with verruca plana treated with 5-fluorouracil,which is similar to our study showing excellent response in $85.94 \%$ patients treated with 5- FU. ${ }^{11}$

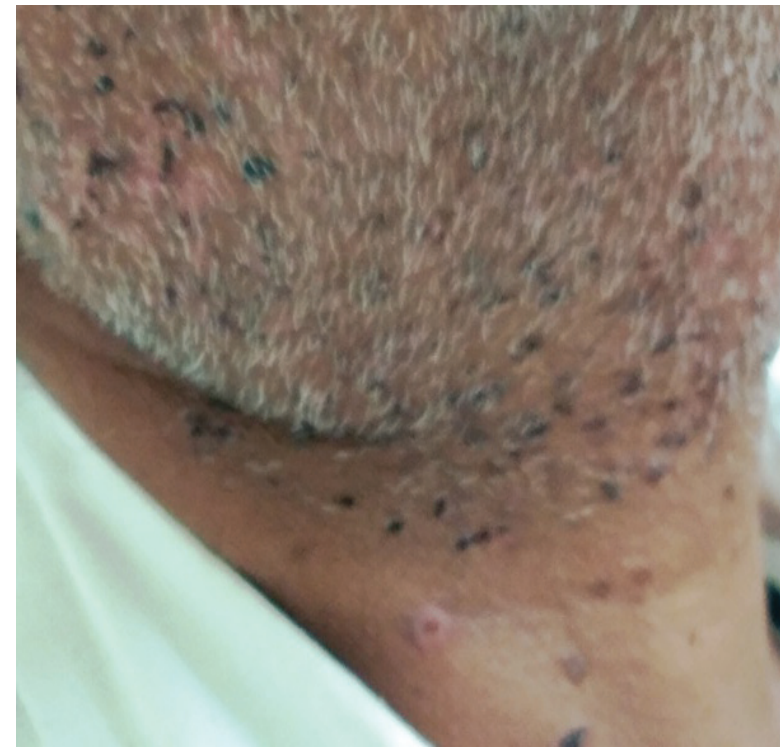

1 week post electrosurgery

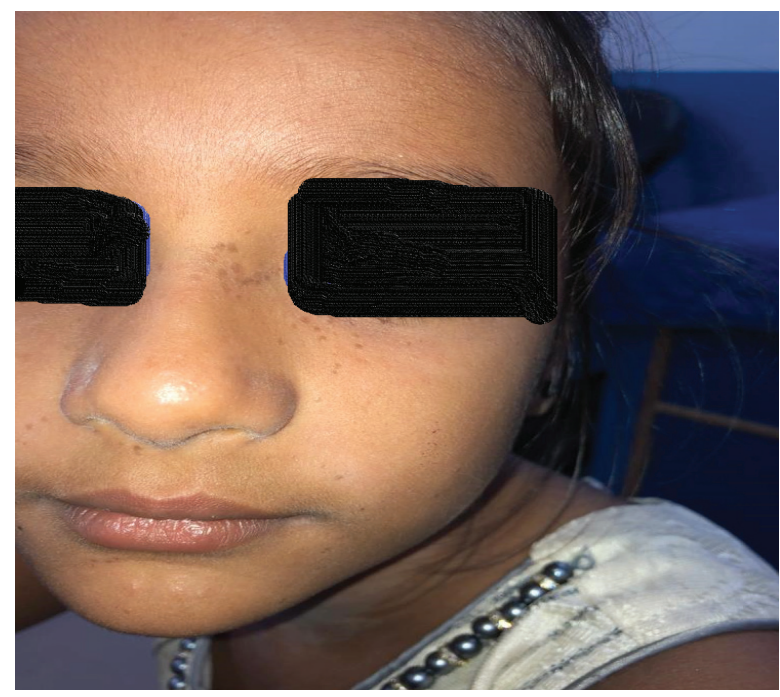

3 weeks post 5 flurouracil

While erythema was the most common side effect in 5-FU and tretinoin groups, pain was the most frequent side effect in Electro-fulguration group. But none of the side effects were severe enough to stop the treatment and hence all patients included in this study came for follow up.

Pain and scarring are frequent with electrosurgery, thus there were less number of patients opting for it.

\section{Conclusion}

All three treatments i.e. $5 \mathrm{FU}$, topical tretinoin and electrosurgery showed excellent response in treatment of plane warts with minimal side effects and any of the treatments can be chosen according to the patient's profile. 


\section{References}

1. Reichman RC, Strike DG. Human papilloma virus infections. Pathogenesis and treatment of human genital papillomavirus infections: A review. Antiviral Research 1989;3(11):109-18. https://doi. org/10.1016/0166-3542(89)90022-3

2. Al Obaidi HK. Topical 5-fluorouracil versus topical tretinoin $0.05 \%$ in treatment of plane wart; a randomized controlled comparative therapeutic trial. Global J Biosci Biotechnol 2013; 2: 368-72.

3. Freedberg, Irwin M., ed. Fitzpatrick's Dermatology in General Medicine. 6th ed. Pp 2123-2124 New York: McGraw-Hill, 2003.

4. Longley DB, Harkin DP, Johnston PG. 5-fluorouracil: mechanisms of action and clinical strategies. Nat Rev Cancer 2003;3(5):330-8. https://doi. org/10.1038/nrc1074

5. Salk RS, Grogan KA, Chang TJ. Topical 5\% 5-fluorouracil cream in the treatment of plantar warts: a prospective, randomized, and controlled clinical study. J Drugs Dermatol 2006;5(5):418-24.

6. Al-Hilo MM, Al-Saedy SJ, Jawad WA. Treatment of plane wart with topical adapaline gel $0.1 \%$ : An open therapeutic trial. JAMS. 2013; 2(2):87-98.
7. Kubeyinje EP. Evaluation of efficacy and safety of $0.05 \%$ tretinoin cream in the treatment of plane warts in Arab children. Journal of dermatological treatment.1996;7(1):21-2. https://doi. org/10.3109/09546639609086864

8. Drake LA, Ceilley RI, Cornelison RL, Dobes WL, Dorner W, Goltz RW, Lewis CW, Salasche SJ, Turner ML, Lowery BJ, Force T. Guidelines of care for warts: human papillomavirus. J Am Acad Dermatol 1995; 32(1):98-103. https://doi. org/10.1016/0190-9622(95)90192-2

9. Blankenship ML. Physical modalities electrosurgery, electrocautery and electrolysis. Int J Dermatol 1979; 18 (6):443-52. https://doi. org/10.1111/j.1365-4362.1979.tb01947.x

10. Dogra A, Gupta SK, Bansal A. Comparative efficacy of topical 5\% 5-fluorouracil with electrosurgery in treatment of warts. Indian J. Dermatol 2006;1; 51 (2):108. https://doi.org/10.4103/00195154.26930

11. Lee S, Kim JG, Chun SI. Treatment of Verruca plana with 5\% 5-Fluorouracil Ointment. Dermatol 1980; 160 (6):383-9. https://doi. org/10.1159/000250527. 